\title{
Erratum to: Heterogeneity of variation of relative risk by age at exposure in the Japanese atomic bomb survivors
}

\author{
Mark P. Little
}

Published online: 28 February 2012

(C) Springer-Verlag 2012

Erratum to: Radiat Environ Biophys (2009) 48:253-262

\section{DOI 10.1007/s00411-009-0228-x}

Equations (1) and (3) in Little (2009) were incorrectly described. The corrected expressions are given below:

$$
\begin{aligned}
& \mathrm{PY}_{i d} \cdot \lambda_{i} \cdot\left[1+\alpha \cdot \exp \left[\delta 1_{s=\text { female }}\right] \cdot D \cdot\left[\frac{a}{50}\right]^{\kappa}\right. \\
& \left.\quad \times \exp \left[\beta_{1}\left(\frac{e-25}{100}\right)+\beta_{2}\left(\frac{e-25}{100}\right)^{2}\right]\right] \\
& \mathrm{PY}_{i j d} \cdot \lambda_{i j} \cdot\left[1+\alpha_{j} \exp \left[\delta_{j} 1_{s=\text { female }}\right] \cdot D \cdot\left[\frac{a}{50}\right]^{\kappa_{j}}\right. \\
& \left.\quad \times \exp \left[\beta_{1 j}\left(\frac{e-25}{100}\right)+\beta_{2 j}\left(\frac{e-25}{100}\right)^{2}\right]\right]
\end{aligned}
$$

(The "100" appearing in the denominators of parts of Eqs. (1) and (3) was incorrectly given as "10" in the original paper.)

The online version of the original article can be found under doi:10.1007/s00411-009-0228-x.

M. P. Little $(\bowtie)$

Radiation Epidemiology Branch, National Cancer Institute,

Rockville MD 20852-7238, USA

e-mail: mark.little@nih.gov 